orange oil 0.5 per cent, fresh yellow carrots $a d$. lib., fresh lemon juice 2 c.c. orally per bird per day, liver extract equivalent to 170 per cent, egg yolk and egg white, alfalfa ash equivalent to 25 per cent, glycerine 4 per cent, cotton pulp 5 per cent and sand 10 per cent. Thus it was shown that copious amounts of the known vitamins, including the anti-hæmorrhagic vitamin, were without influence on gizzard erosion.

Gizzard erosion is not a portion of the hæmorrhagic syndrome, but is a separate deficiency disease which may be corrected by a new fat-soluble factor found in the saponifiable fraction and probably vitamin in Nature. Studies on this anti-gizzard. erosion factor are being continued.

H. J. Almquist.

E. L. R. STOKSTAD.

Division of Poultry Husbandry,

University of California, Berkeley.

1 Dam, H., NATURE, 135, 652 (1935).

2 Dam, H., Biochem. J., 29, 1273 (1935)

3 Almquist, H. J., and Stokstad, E. L. R., NATURE, 136, 31 (1935). Almquist, H. J., and Stokstad, E. L. R., J. Biol. Chem., 111, 105 (1935).

'Jungherr, E., Conn. Agr. Exp. Sta. Bul., 202, 52 (1935).

\section{Humic Composts and Inorganic Fertilisers}

Sir Albert Howard's lecture before the Royal Society of Arts on November 14 last on "The Manu. facture of Humus by the Indore Process" has been followed by several inquiries as to the attitude of the Indore Institute of Plant Industry towards the question of the comparative value to crops of inorganic fertilisers and composts. It therefore seems desirable to define that attitude by a definite and public statement.

Regarding the maintenance of soil organic matter at its optimum level as one of the aims of soil management, we consider this can generally be best achieved by the use of humic composts. These are easily and cheaply made from organic wastes on farms and plantations by a judicious application of the fundamental principles underlying their aerobic decomposition. Such humic composts will naturally contain some plant nutrients, which should be conserved so far as is compatible with a high yield of humified material, which it is the prime function of composts to supply.

Table 1. Yield of green fodder (total of three cuttings). Lucerne.

\begin{tabular}{|c|c|c|c|c|c|c|c|}
\hline \multirow[t]{2}{*}{ Yield } & \multicolumn{3}{|c|}{$\begin{array}{l}\text { Well-rotted dung } \\
\text { manure } \\
(\mathrm{N}=0 \cdot 371 \text { per } \\
\text { cent : } \mathrm{P}_{2} \mathrm{O}_{6}= \\
0.69 \text { per cent }) .\end{array}$} & \multicolumn{3}{|c|}{$\begin{array}{c}\text { Municipal } \\
\text { compost } \\
\left(\mathrm{N}=0^{\circ} \cdot 44 \text { per }\right. \\
\text { cent } ; \mathbf{P}_{2} \mathrm{O}_{5}= \\
\mathbf{1} \cdot 27 \text { per cent }) .\end{array}$} & \multirow{2}{*}{$\begin{array}{l}\text { Well-rotted } \\
\text { dung man- } \\
\text { ure (10 } \\
\text { carts/acre) } \\
\text { Super (762 } \\
\text { lb./acre). }\end{array}$} \\
\hline & \multicolumn{3}{|c|}{$\begin{array}{c}\text { Carts per acre } \\
10 \quad 20\end{array}$} & \multicolumn{3}{|c|}{$\begin{array}{llr}\text { Carts per acre } \\
10 & 20 & 30\end{array}$} & \\
\hline Mds. per acre & 387 & 411 & 429 & 351 & 405 & 476 & 429 \\
\hline
\end{tabular}

$P<0.05 ;$ signiflcant difference 73 .

Under certain conditions crops may respond to nutrients contained in composts equally well or better than to those in inorganic fertilisers (Table 1). Under other conditions it may be otherwise, but it seems that for the most efficient utilisation of added inorganic nutrients a certain level of soil organic matter content - which may or may not be found in a given soil--is necessary for each crop. This is illustrated by the following pot-culture results on cotton. Such pot-culture results have been confirmed by field trials on several crops.
Table 2. Yield of seed cotton (gm. per plant). Pot culture experiment $1934-35$.

\begin{tabular}{|c|c|c|c|c|}
\hline \multirow[b]{2}{*}{ Nutrients } & \multicolumn{2}{|c|}{ Cambodia (Indore 1) } & \multicolumn{2}{|c|}{ Malvi 9} \\
\hline & No treatment & Compost & No treatment & Compost \\
\hline Nil & $3 \cdot 5$ & $4 \cdot 9$ & $2 \cdot 8$ & $6 \cdot 3$ \\
\hline $\mathbf{N}$ & $4 \cdot 8$ & $14 \cdot 0$ & $3 \cdot 2$ & $13 \cdot 9$ \\
\hline & $10 \cdot 7$ & $6 \cdot 8$ & $2 \cdot 7$ & $6 \cdot 3$ \\
\hline & $7 \cdot 7$ & $19 \cdot 2$ & $2 \cdot 3$ & $9 \cdot 9$ \\
\hline $\mathbf{N}, \mathrm{P}$ & $15 \cdot 6$ & $18 \cdot 7$ & $1 \overline{5} \cdot 2$ & $12 \cdot 7$ \\
\hline & $8 \cdot 6$ & $13 \cdot 7$ & $3 \cdot 9$ & $13 \cdot 4$ \\
\hline
\end{tabular}

$P<0.01 ;$ signiflcant difference $=2 \cdot 4$.

Rates of manures used per kilogram of soil.

Compost : to supply $200 \mathrm{mgm}$. of $\mathrm{N}$.

$\mathbf{N}, \mathbf{K}, \mathbf{P}$ : ", , of each.

Hence, in our view, humic composts do not necessarily compete with inorganic fertilisers; rather they are complementary to each other.
Y. D. WAD.

F. K. JACKSON.

Institute of Plant Industry,

Indore, India.

Feb. 12.

\section{The Nature of Light}

SIR J. J. Thomson ${ }^{1}$ has suggested that a photon is a finite, harmonic train of circular lines of electric force originating when an electron in a radiating atom falls from one energy-level to another. Such circular lines of force would move at right angles to their planes, and their centres would travel along a straight line with the velocity of light. If a set of electromagnetic waves of the kind suggested could exist, the energy in any wave-front could be concentrated around the axis of propagation, so that the radiation could be confined within a cylindrical pencil and would not be dissipated through space. The 'photon' would therefore travel unchanged without loss of energy.

It seems to be quite impossible, however, that the solutions of Maxwell's equations propounded by Thomson can exist in any reasonable medium.

The electric intensity of the circular lines of force obeys an expression of the form $Q=A \rho+B / \rho$, where $A$ and $B$ are constants and $\rho$ is the usual radius vector of cylindrical co-ordinates. To satisfy conditions of finiteness, there must exist an un. pleasantly arbitrary value of $\rho(=a)$, such that $B=0$ when $\rho<a$ and $A=0$ when $\rho>a$. Out. side this 'core' of radius $a$, the magnetic vector, $\gamma$, parallel to the axis of propagation, vanishes, and there is no radial flow of energy. Inside the 'core', however, $\gamma$ is finite and constant, and there is a radial flow of energy, which, presumably, would have to be dissipated at the mathematical surface, $p=a$. This difficulty, of course, is to be traced back to the fact that, although Thomson has made the tangential electric vector continuous in crossing the arbitrary interface, he has not satisfied the continuity condition for the tangential magnetic vector at the same bound. ary. This last condition can be complied with only if $A=0$. As a consequence, $Q$ can be finite every. where only if it vanishes everywhere.

Such cylindrical wave-trains can exist therefore only if, imbedded in the propagating medium, there is a perfectly conducting surface at $\rho=a$.

Jesus College,

C. Hurst.

Oxford.

Feb. 14.

NATURE, 137, 232 (Feb. 8, 1936). 